\title{
O IMPACTO DAS NOVAS TECNOLOGIAS NA DEMANDA DA GRAFITA ${ }^{1}$
}

Eduardo Vale ${ }^{2}$

\section{SINOPSE}

O texto apresenta uma síntese do estudo sobre a grafita $(\mathrm{C})$ preparado pelo Ipea no âmbito da cooperação institucional (TED) com o MME. O relatório de pesquisa oferece um diagnóstico horizontal, embora focado em tópicos selecionados, e uma análise do impacto das novas tecnologias na demanda da grafita. A partir da análise da situação atual, são discutidos cenários prospectivos, de modo a referenciar as sugestôes de políticas e açôes setoriais de governo especificamente direcionadas à cadeia industrial da grafita.

Palavras-chave: economia mineral; aquecimento global; grafita; mineração; eletrificação; baterias; energias renováveis.

\section{AQUECIMENTO GLOBAL}

Os esforços internacionais direcionados à redução do aquecimento global configuram processo em curso acelerado e irreversível. Em diversos países, estão sendo implementadas políticas públicas direcionadas à redução do consumo de combustíveis fósseis, ao aumento do uso de energias renováveis e à substituição de veículos movidos à combustão para veículos elétricos. Essas políticas, diga-se de passagem, estão no centro da agenda de política econômica pós-Covid-19 de vários países desenvolvidos como eixo central do processo de retomada do crescimento.

As açôes planejadas enfatizam o aumento no uso das energias solar e eólica e o fomento à transição para veículos elétricos e híbridos. A gravidade da ameaça representada pelo aquecimento global aumentou a urgência do emprego de fontes renováveis que ajudem a descarbonizar a matriz energética. Em paralelo, avança de forma célere a demanda por veículos elétricos e híbridos - de passageiros e também de carga -, estimulando o processo conhecido como eletrificação da economia.

\section{INICIATIVAS INSTITUCIONAIS}

O relatório Minerals for Climate Action: the mineral intensity of the clean energy transition, publicado pelo Banco Mundial, estimou o impacto na demanda de bens minerais selecionados provenientes da expansão global esperada das energias eólica e solar, assim como da demanda por baterias até 2050 (Hund et al., 2020). Esses vetores são considerados fundamentais para alcançar a meta global de redução mínima de $2{ }^{\circ} \mathrm{C}$ no processo de aquecimento. O estudo incluiu a grafita no grupo dos minerais de grande impacto: "bens minerais utilizados por grupo restrito de tecnologias".

A grafita é destacada pelo uso fundamental na produção do anodo utilizado nas baterias de íon-lítio destinadas aos veículos elétricos e ao armazenamento em larga escala da energia gerada pelas fontes renováveis. As estimativas do Banco Mundial apontam para um crescimento de 383\% na demanda de grafita até 2050.

1. DOI: http://dx.doi.org/10.38116/radar65art3

2. Pesquisador do Subprograma de Pesquisa para o Desenvolvimento Nacional (PNPD) na Diretoria de Estudos e Políticas Setoriais de Inovação e Infraestrutura (Diset) do Ipea. E-mail: <edu.bamburra@gmail.com>. 
A figura 1 apresenta os impactos estimados pelo Banco Mundial na demanda de vários bens minerais para o período que vai de 2017 a 2050.

Nos exercícios prospectivos do Banco Mundial, fica evidenciada a interdependência entre a expansão dos sistemas econômicos baseados na adoção das novas tecnologias e o aumento expressivo na produção mineral global que será requerido. Trata-se de processo intensivo no emprego de bens minerais e cuja intensidade será ampliada. Por outro lado, a expansão da mineração global, em resposta ao impacto da demanda derivada da adoção e disseminação das novas tecnologias, deverá ocorrer, concomitantemente, sob os paradigmas da sustentabilidade e da transição operacional comprometida com a minimização da emissão de carbono.

De acordo com a Agência Internacional de Energia (AIE), a implementação de marcos regulatórios e de medidas fiscais por países desenvolvidos assume papel cada vez mais relevante, tanto no fomento à aceleração das taxas de penetração das energias renováveis na matriz energética global quanto no aumento da frota de veículos elétricos. No âmbito da União Europeia (UE), o lançamento do plano de recuperação econômica European Green Deal contempla investimentos de aproximadamente US\$ 826 bilhóes. O foco é a redução da emissão de $\mathrm{CO}_{2}$, de modo a tornar a UE neutra, do ponto de vista climático, em 2050.

\section{FIGURA 1}

Demanda de bens minerais

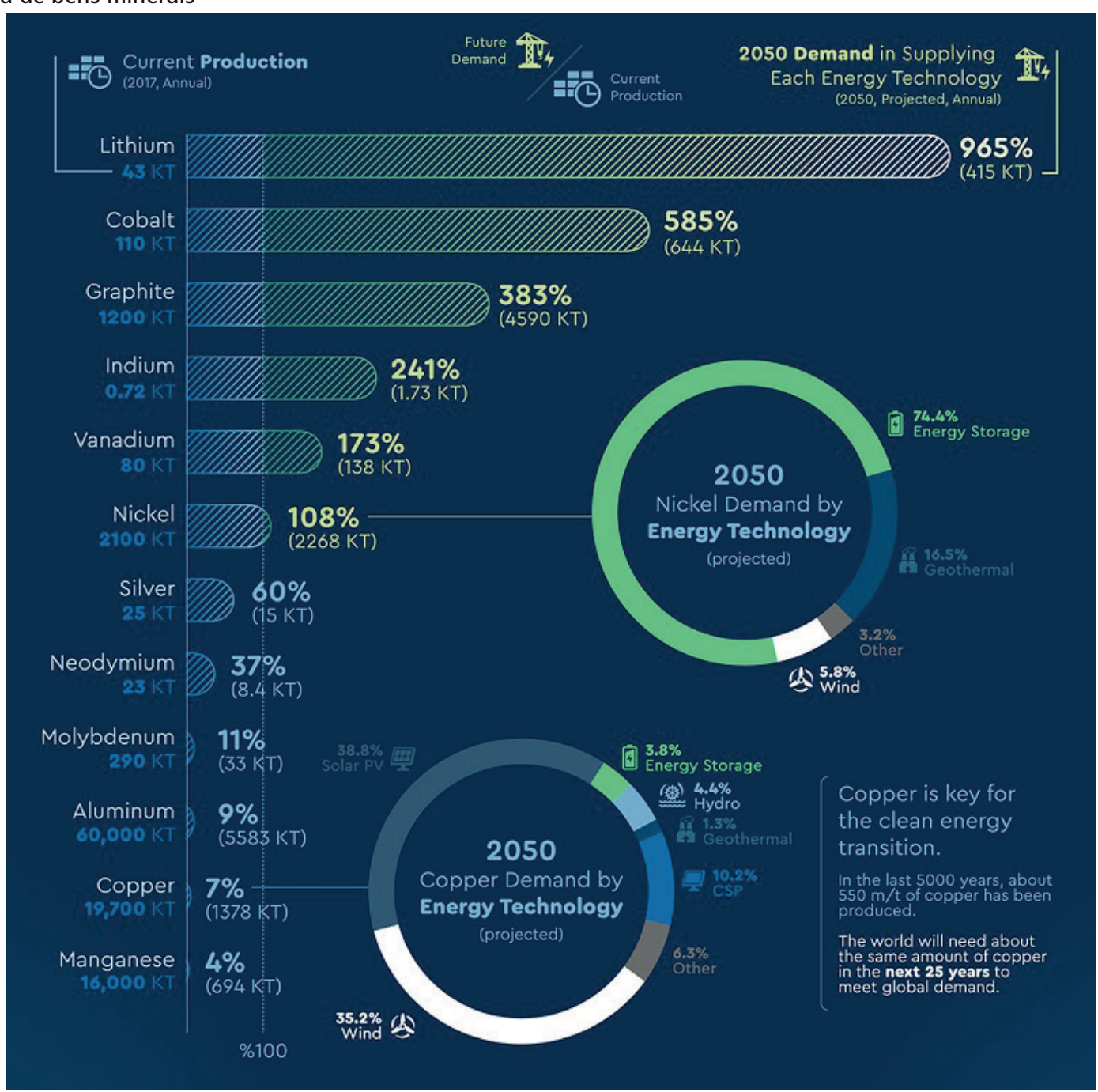

Fonte: Climate-smart mining: minerals for climate action. Disponível em: <https://bit.ly/3uP1JLh>.

Obs.: Figura cujos leiaute e textos não puderam ser padronizados e revisados em virtude das condições técnicas dos originais (nota do Editorial). 
Por sua vez, a Comissão Europeia lançou o documento Resiliência em Matérias-Primas Essenciais (2020), com os seguintes objetivos: i) identificar desafios atuais e futuros para a redução da dependência externa da Europa em materiais críticos; ii) diversificar fontes de suprimento; iii) assegurar o uso eficiente dos recursos; e iv) adotar fundamentos de economia circular em condiçôes de sustentabilidade. Nesse contexto, cabe ainda mencionar a criação das seguintes entidades: Global Battery Alliance (GBA), European Battery Alliance (EBA) e European Raw Materials Alliance (ERMA).

\section{CONSUMO DE GRAFITA}

Muito embora a grafita $(\mathrm{C})$ seja um mineral não metálico, ela apresenta várias propriedades dos minerais metálicos. Seu amplo espectro de características proporciona uma gama diversificada de aplicaçóes industriais e tecnológicas, tais como:

- refratários para a fundição contínua, eletrodos, produção de extrudados, pós-metálicos e elevação do teor de carbono;

- aplicaçóes em reatores nucleares e compósitos de alta resistência para energia eólica;

- indústria aeroespacial;

- anodo para baterias (o anodo tem a função de armazenar e liberar os íons de lítio para a corrente elétrica); e

- lápis, lubrificantes, retardantes de fogo e materiais de fricção, escovas de motores elétricos.

Na sequência, tem-se o perfil setorial agregado do consumo global: refratários (35\%); baterias (25\%); lubrificantes e fundição (10\%); siderurgia (7\%); lápis (4\%); outros (19\%).

Atualmente, cerca de dois terços da demanda por concentrado de grafita é derivada do setor industrial, e um terço do segmento de baterias. No período que vai de 2012 a 2019, a participação relativa das baterias no consumo de grafita aumentou cerca de $150 \%$. Para os próximos dez anos, pelo menos, as perspectivas para a demanda de grafita são excelentes. Segundo a empresa Benchmark Mineral Intelligence (2020), o segmento de baterias deverá responder por cerca de $50 \%$ da demanda por volta de 2025 , alcançando $75 \%$ ao final da década.

No que diz respeito aos demais segmentos consumidores, tais como refratários, lubrificantes, fundição e pósmetálicos, entre outros, as expectativas são de crescimento moderado na faixa de 5\% a 7\% ao ano. Destaque-se que a demanda de grafita como insumo para retardante de fogo deverá apresentar crescimento acima da média dos demais segmentos consumidores por conta do avanço no arcabouço legal específico.

A partir dessas consideraçóes, o vetor de crescimento fundamental da demanda de grafita, ao longo dessa década, é o segmento de baterias do tipo íon-lítio para veículos elétricos e híbridos (de duas, três ou quatro rodas), para armazenamento de energia em larga escala e para o segmento de produtos eletrônicos em geral.

\section{SITUAÇÃO DA GRAFITA NO BRASIL}

No Brasil, a grafita está inserida no grupo de minerais estratégicos por suas aplicaçóes em produtos e processos de alta tecnologia. Segundo o United States Geological Survey (USGS), as reservas brasileiras estão estimadas em 72 milhóes de toneladas. As reservas de grafita do país representam $24 \%$ das reservas mundiais. No que diz respeito à produção, a estimativa do USGS é de 96 mil toneladas de carbono grafítico $(\mathrm{Cg})$. 
Por outro lado, a dimensão do mercado interno potencial para baterias de íon-lítio, a magnitude e a diversificação do setor industrial e os avanços tecnológicos em curso posicionam a grafita entre os minerais prioritários para a política mineral. Tanto o setor público quanto o privado possuem diversas açóes voltadas para o mineral, com destaque para as seguintes:

- projeto Avaliação do Potencial da Grafita no Brasil, fase 1 - PAPGB (Sousa e Matos, 2020);

- Inova Mineral - plano de desenvolvimento, sustentabilidade e inovação do setor de mineração e transformação mineral (MME, ABDI, MCTI, CETEM, MDIC, empresas e ICTs);

- Política de Apoio ao Licenciamento Ambiental de Projetos de Investimentos para a Produção de Minerais Estratégicos;

- Grupo de Trabalho Brasil-Estados Unidos "para avançar a cooperação bilateral em minerais essenciais para a segurança, a prosperidade e o desenvolvimento sustentável de ambos os países”; ${ }^{3}$

- início da produção de baterias do tipo fosfato-lítio-ferro (LFP) no Polo Industrial de Manaus pela empresa chinesa BYD;

- instalação de fábrica para produção de células de baterias de lítio-enxofre na cidade de Juiz de Fora (MG) pela empresa britânica Oxis Energy;

- criação do MackGraphe - centro de pesquisas avançadas em grafeno, nanomateriais e nanotecnologias; ${ }^{4} \mathrm{e}$

- projeto MGgrafeno - implementaçáo da primeira planta-piloto de grafeno do Brasil pela Companhia de Desenvolvimento do Estado de Minas Gerais, em parceria com o Centro de Desenvolvimento da Tecnologia Nuclear/Comissão Nacional de Energia Nuclear e com a Universidade Federal de Minas Gerais. ${ }^{5}$

\section{COMENTÁRIOS FINAIS}

Em vários países desenvolvidos, as políticas direcionadas à redução do consumo de combustíveis fósseis e à eletrificação da economia integram o eixo central do processo de retomada do crescimento. Trata-se de processo intensivo no uso de bens minerais. Para os governos desses países, sob as óticas da segurança nacional e da garantia de suprimento, a dinâmica, as sinergias e a transcendência global da agenda sobre o clima alçaram a grafita à categoria de mineral crítico. Nesse contexto, ressalta-se a concentração geográfica em termos de origem e destinação desse mineral, especialmente no que concerne ao processamento químico-industrial situado na Ásia.

A magnitude das reservas de grafita do Brasil, as inúmeras aplicaçôes industriais, a dimensão do mercado interno potencial para baterias de íon-lítio e a produção de materiais e produtos avançados, como os derivados do grafeno, apontam para a oportunidade de agregação de valor na cadeia industrial do país.

Os fundamentos da demanda no longo prazo parecem sólidos e bem colocados. Ao longo da década, as perspectivas para a demanda de grafita são excelentes. O segmento de baterias deverá responder por cerca de $50 \%$ da demanda por volta de 2025, alcançando $75 \%$ em 2030. A empresa de consultoria Benchmark Mineral Intelligence estima uma demanda de anodo ao redor de 2,2 milhóes de toneladas, em 2024, ultrapassando 3,5 milhôes de toneladas ao final da década. O aumento da participação da grafita natural parece inevitável, tendo em vista o seu custo de produção mais baixo (custo de energia) e sua estrutura de produção mais sustentável, em comparação à grafita sintética.

3. Disponível em: <https://bit.ly/3v5dflv>.

4. Disponível em: <https://www.mackenzie.br/en/mackgraphe/>.

5. Disponível em: <https://www.mggrafeno.com.br/>. 
Ao longo dos últimos dez anos, em que pese a entrada de outros produtores, a produção de grafita natural manteve-se relativamente estável. Contudo, é inegável que, a despeito das altas taxas de crescimento da demanda pelo setor de baterias, os níveis de preços da grafita não sinalizam, até o presente, o impacto dessa demanda adicional. As principais consultorias especializadas não vislumbram aumentos de preços até que a demanda alcance patamares capazes de pressionar a capacidade instalada prevista.

É oportuno registrar que essas estimativas antecederam o resultado das eleiçóes americanas. Conforme anunciado pelo governo eleito, haverá uma ênfase no aprofundamento do processo de eletrificação e do desenvolvimento de energias renováveis. $\mathrm{Na}$ ausência de aumentos substanciais da produção mundial de grafita, considerando as elevadas taxas de crescimento esperadas para a demanda de grafita, esperam-se um mercado deficitário, já a partir de 2024, e uma trajetória de crescimento acelerada.

Em nível de sugestóes, pelo lado do suprimento, cabe acelerar o conhecimento do potencial de grafita do país em escala e formatação compatíveis com as necessidades dos projetos de exploraçáo mineral do setor privado. Pelo lado da produção mineral, dinamizar a liberação de direitos minerários referentes à grafita.

Sob a ótica da tecnologia, é fundamental dispor de uma visão agregada da carteira de projetos de pesquisa relacionados à grafita. A realização de inventário dos projetos já executados, em execução ou previstos pode ser muito útil. O objetivo é posicionar o governo acerca da situação atual e oferecer maior lucidez sobre a eficácia e a aderência da alocaçáo dos recursos às prioridades do país. Nesse contexto, a análise das oportunidades e dos obstáculos e o desenvolvimento de estratégia voltada para aumento da agregação de valor ao longo da cadeia industrial da grafita sugerem as etapas de micronização e de produção da grafita esférica purificada como objetivos a serem perseguidos.

Considerando a expansão acelerada das energias eólica e solar, a demanda por baterias para armazenamento já está colocada. Falta aprofundar o conhecimento sobre esse vetor, sua dinâmica e suas implicaçóes. Assim sendo, sugere-se a realização de estudo prospectivo sobre a demanda potencial de grafita para o segmento de baterias. Não obstante, tendo em vista as inúmeras aplicaçóes industriais, o escopo do estudo deve ser mais amplo e oferecer suporte à definição de uma política mineral específica para a cadeia industrial de valor da grafita.

\section{REFERÊNCIAS}

BENCHMARK MINERAL INTELLIGENCE. Lithium ion battery megafactories assessment. London: Benchmark, Nov. 2020.

COMISSÃO EUROPEIA. Resiliência em matérias-primas essenciais: o caminho a seguir para mais segurança e sustentabilidade. Bruxelas: Comissão Europeia, 3 set. 2020. (Comunicado, n. 474). Disponível em: <https://bit.ly/2P6MUVp>. HUND, K. et al. Minerals for climate action: the mineral intensity of the clean energy transition. Washington: World Bank, 2020. Disponível em: <https://bit.ly/3dhUuG3>.

SOUSA, M. J.; MATOS, D. R. (Org.). Projeto Avaliaçáo do Potencial da Grafita no Brasil: fase 1. São Paulo: CPRM, 2020. (Série Minerais Estratégicos, n. 5). Disponível em: <http://rigeo.cprm.gov.br/jspui/handle/doc/21910>.

VALE, E. Impacto das novas tecnologias na demanda mineral: o caso da grafita. Brasília: Ipea, dez. 2020. 86 p. 
